\title{
Efficacy and Safety of Sublingual Versus Vaginal Misoprostol for Pre-induction Cervical Ripening Among Primigravida
}

\section{Indira Acharya', Sumana Thapa1 and Pushpa Chaudhary ${ }^{2}$}

${ }^{1}$ Department of Gynecology, Nepalese Army Institute of Health Sciences, Shree Birendra Hospital, Chhauni, Kathmandu, Nepal

2Paropakar Maternity \& Women's Hospital, Thapathali, Kathmandu, Nepal

\section{ABSTRACT}

Background: Induction of labor is an intervention intended to artificially initiate uterine contractions resulting in progressive effacement and dilatation of the cervix. This is a common intervention during pregnancy in both industrialized and non-industrialized countries. Misoprostol is the commonly used induction agent. The objective of this study was to compare the efficacy of sublingual route of misoprostol with that of vaginal for pre-induction cervical ripening at term among Primigravida.

Methods: This study was a hospital based cross sectional comparative study, conducted at a tertiary maternal care center, Kathmandu over a period of 6 months extending from July 2010 to December 2010. Primigravida at 40-42 weeks of gestation who met the inclusion criteria were enrolled in this study and were randomly enrolled for sublingual misoprostol and vaginal misoprostol.

Results: More women in the vaginal misoprostol group had Bishop score more than six after 8 hours of insertion of first dose $(80 \%)$ compared to those who received sublingual misoprostol (48\%). The mean induction to delivery interval was shorter in the vaginal misoprostol group (12.12 hours) compared to (12.96) in sublingual group. Use of oxytocin for augmentation of labour was required more in the sublingual group but the difference was not significant statistically

Conclusions: Both sublingual and vaginal routes of misoprostol administration were equally effective and appeared safe for pre-induction cervical ripening at term.

Key words: sublingual misoprostol, vaginal misoprostol, vaginal delivery

Correspondence: Indira Acharya, Department of Gynaecology, Nepalese Army Institute of Health Sciences, Shree Birendra Hospital, Chhauni, Kathmandu, Nepal. E-mail: acharyaa.indira@gmail.com

DOI: http://dx.doi.org/10.3126/mjsbh.v17i1.17882

Submitted on: 2017-07-30

Accepted on:2017-10-26 


\section{INTRODUCTION}

Introduction of labour can be defined as an intervention intended to artificially initiate uterine contractions resulting in the progressive effacement and dilatation of the cervix. ${ }^{1}$ It is a common intervention in obstetrics, both in industrialized and non-industrialized countries. ${ }^{2,3}$ Success of induction leading to vaginal delivery depends largely on the state of cervix; induction in an unripe cervix often results in failure. Induction is associated with increased risk of prolonged labour, febrile morbidity and caesarean delivery rate if cervix is not favorable. ${ }^{4}$ Numerous physical and hormonal methods have been tried in past and recently, prostaglandins have been tried.., 5

Prostaglandins are the current drug of choice and have been tried for cervical ripening and labour induction in pregnant women with an unfavourable cervix. ${ }^{6}$ Misoprostol has been extensively and successfully used for labour induction due to its efficacy, low cost and stability at room temperature. ${ }^{7}$ Oral, vaginal or sublingual are possible routes, and client acceptability of misoprostol for cervical ripening and labour induction is increasing. ${ }^{8}$ Vaginal misoprostol has been studied extensively and has been shown to be an effective method of pre induction cervical ripening. ${ }^{9}$ Sublingual route of misoprostol has been less extensively studied for induction of labour, though this route is appealing for several reasons, including the convenience, lack of invasiveness and a higher patient's acceptability. ${ }^{10}$ Preliminary reports showed that misoprostol could be used sublingually for induction, and was found to be effective and well tolerated. ${ }^{11,12}$

Intravaginal misoprostol is being extensively used for induction of labour in our institute and till date no study has been conducted with sublingual misoprostol. This study was done to explore whether sublingual misoprostol may be tried as a new option for induction of labour comparing the efficacy of administration of sublingual misoprostol with vaginal misoprostol for preinduction cervical ripening at term among Primigravida.

\section{METHODS}

This was a cross sectional comparative study, comparing efficacy and safety of sublingual and vaginal routes of administration of misoprostol conducted at tertiary level maternity hospital, Kathmandu, Nepal for a duration of 6 months from July 2010 to December 2010. During this period, 100 Primigravidas at 40-42 weeks of gestation with singleton pregnancy having Bishop score $<6$ and who expressed willingness to participate and gave informed written consent were enrolled for this study. While, pregnant lady with known allergy to prostaglandin, cephalo-pelvic disproportion, antepartum hemorrhage, previous uterine surgery, cardiac disease, asthma, hypertension, fetal distress, fetal anomaly, premature rupture of membrane, intrauterine growth restriction (IUGR), and any contraindication to vaginal delivery were excluded from study cohort. Pre-tested verified questionnaire was used for data collection. Collected data were entered analysis was done using SPSS version 17. Chi-square test was used for statistical association. Study was conducted after approval from local institutional ethical review committee.

The enrolled cases were randomly allocated in two groups; one received $50 \mathrm{mcg}$ of sublingual misoprostol and next received $50 \mathrm{mcg}$ of vaginal misoprostol. Both groups received two doses of misoprostol (each dose containing $50 \mathrm{mcg}$ of misoprostol) 4 hours apart and the drug was administered sublingually or vaginally according to allocated group. Second dose of misoprostol was withheld if there was sign of uterine contraction or fetal distress, spontaneous rupture of membrane. 
Table 1. Change in Bishop Score

\begin{tabular}{|l|l|l|l|}
$\begin{array}{l}\text { Bishop } \\
\text { score after } 8 \\
\text { hrs of first } \\
\text { dose of } \\
\text { misoprostol }\end{array}$ & $\begin{array}{l}\text { Sublingual } \\
(\mathrm{n}=50)\end{array}$ & $\begin{array}{l}\text { Vaginal } \\
(\mathrm{n}=50)\end{array}$ & $\begin{array}{l}\mathrm{p} \\
\text { value }\end{array}$ \\
\hline Unchanged & $26(52 \%)$ & $10(20 \%)$ & 0.002 \\
\hline $\mathbf{6 - 8}$ & $14(28 \%)$ & $29(58 \%)$ & \\
\hline$>8$ & $10(20 \%)$ & $11(22 \%)$ & \\
\hline Total & $50(100 \%)$ & $50(100 \%)$ & \\
\hline
\end{tabular}

Second dose of misoprostol was not given if Bishop score was six or more. Privacy and confidentially were maintained properly. Per vaginal examination was done to assess Bishop score. Fetal heart sound (FHS) and uterine contraction were monitored regularly by attending staff. Women were advised to lie on left lateral position, record fetal movement count and inform staff on duty in case of $\mathrm{P} / \mathrm{V}$ leaking, decreased fetal movement and frequent uterine contractions with increasing intensity.

Partograph was maintained in active phase of labour. Labour was augmented with oxytocin in the coming morning if she did not deliver by next morning. Decision regarding analgesia and oxytocin augmentation was made by on duty registrar. Patients, who developed irregular FHS, were hydrated and given oxygen inhalation. Close monitoring of the fetal heart sound was done for half an hour. If FHS became regular, patients were given second dose of misoprostol. If FHS remained irregular or there was presence of meconium stained liquor in case of SROM, further dose of misoprostol was withheld and patient was prepared for emergency caesarean section.

\section{RESULTS}

Majority of women were between the age of 20-24 years in both groups (27 in sublingual and 32 in vaginal), followed by 25-29 years (16 and 14
Table 2. Need of oxytocin for augmentation of labour

\begin{tabular}{|l|l|l|r|}
\hline Oxytocin & $\begin{array}{l}\text { Sublingual } \\
\text { misoprostol } \\
\text { 50mcg } \\
(\mathrm{n}=50)\end{array}$ & $\begin{array}{l}\text { Vaginal } \\
\text { Mlisoprostol } \\
50 \mathrm{mcg} \\
(\mathrm{n}=50)\end{array}$ & $\begin{array}{l}\mathrm{p} \\
\text { value }\end{array}$ \\
\hline Yes & $25(50 \%)$ & $17(34 \%)$ & 0.09 \\
\hline No & $25(50 \%)$ & $33(66 \%)$ & \\
\hline Total & $50(100 \%)$ & $50(100 \%)$ & \\
\hline
\end{tabular}

respectively). In the sublingual group, 10 had Bishop score $>$ eight after eight hours of the drug insertion compared to 11 cases in the vaginal group. Only ten women had Bishop score unchanged after eight hours in the vaginal group compared to 26 in the sublingual group $(p=0.002)$ (Table 1).

Bishop score prior to induction was $4.14 \pm 0.85$ in sublingual and vaginal group, which was nonsignificant $(p=0.51)$. However, after eight hours of first dose of misoprostol it was significantly more in vaginal group $(6.42 \pm 1.33)$ compared to sublingual group $(5.48 \pm 1.18)(\mathrm{p}=0.001)$. Oxytocin was needed for augmentation of labour in 17 cases in vaginal group compared with the 25 cases in sublingual group. Overall, $43 \%$ of women needed oxytocin for augmentation where as rest did not (Table 2).

Among sublingual group three delivered within six hours of induction; seven in 6-12 hours, 14 within 24 hours and 26 after 24 hours of induction. Whereas ten women delivered within 6-12 hours, 16 within 24 hours and 24 after 24 hours of induction. Mean time interval between administration of first dose of misoprostol was lower in vaginal group ( $23.06 \pm 10.93$ ) compared to sublingual group $(24.77 \pm 12.81)$ but this finding was statistically non-significant $(\mathrm{p}=0.47)$. In most cases pregnancy terminated by spontaneous vaginal delivery while in some cases from both groups 


\begin{tabular}{|l|l|l|r|r|}
\hline \multicolumn{5}{|c|}{ Table 3. Mode of delivery } \\
\hline $\begin{array}{l}\text { Mode } \\
\text { of } \\
\text { delivery }\end{array}$ & $\begin{array}{l}\text { Sublingual } \\
\text { group } \\
(\mathrm{n}=50)\end{array}$ & $\begin{array}{l}\text { Vaginal } \\
\text { group } \\
(\mathrm{n}=50)\end{array}$ & Total & $\begin{array}{l}\text { P } \\
\text { value }\end{array}$ \\
\hline SVD & $37(74 \%)$ & $42(84 \%)$ & 79 & 0.21 \\
\hline $\begin{array}{l}\text { Vacuu } \\
\text { m }\end{array}$ & $5(10 \%)$ & $3(6 \%)$ & 8 & 0.46 \\
\hline LSCS & $8(16 \%)$ & $5(10 \%)$ & 13 & 0.37 \\
\hline Total & $50(100 \%)$ & $50(100 \%)$ & 100 & \\
\hline
\end{tabular}

needed LSCS or vacuum assisted delivery. There were eight cases of caesarean delivery in the sublingual group and five cases in the vaginal group (Table 3). The indication of caesarean delivery was almost similar and included fetal distress, failed induction, and non-progress of labour.

Mean Apgar score after five minutes of delivery was more in the sublingual group $(8.04 \pm 0.92)$ in comparison to vaginal group $(7.62 \pm 1.17)$ $(\mathrm{p}=0.05)$. Nine babies $(18 \%)$ in the vaginal group needed admission to special care baby unit (SCBU) compared to five babies (10\%) in the sublingual group. In vaginal group, in 12 cases $(24 \%)$ there was thin meconium and thick meconium in seven $(14 \%)$ while only in nine cases $(18 \%)$ there was thin meconium in sublingual group and neither had thick meconium $(p=0.006)$. There were three neonatal deaths in the vaginal group and one in the sublingual group. In the sublingual group, nausea was significantly higher in comparison with vaginal group $(p=0.004)$. Other adverse events were vomiting and fever in some cases (Table 4).

\section{DISCUSSION}

Misoprostol has been proved to highly effective for pre-labor cervical ripening in many studies but ideal dose and route of administration for efficacy as well as safety is still being explored. There is plenty of evidence supported by studies about
Table 4. Maternal side effects and fetal complications

\begin{tabular}{|l|l|l|l|}
\hline Events & $\begin{array}{l}\text { Sublingual } \\
\text { group } \\
(\mathrm{n}=50)\end{array}$ & $\begin{array}{l}\text { Vaginal } \\
\text { group } \\
(\mathrm{n}=50)\end{array}$ & $\begin{array}{l}\mathrm{P} \\
\text { value }\end{array}$ \\
\hline $\begin{array}{l}\text { SCBU } \\
\text { Admission }\end{array}$ & $5(10 \%)$ & $9(18 \%)$ & 0.240 \\
\hline Thin MSL & $9(18 \%)$ & $12(24 \%)$ & 0.460 \\
\hline Thick MSL & $0(0 \%)$ & $7(14 \%)$ & 0.006 \\
\hline Neonatal death & $1(2 \%)$ & $3(6 \%)$ & 0.610 \\
\hline Nausea & $10(20 \%)$ & $1(2 \%)$ & 0.004 \\
\hline Vomiting & $5(10 \%)$ & $1(2 \%)$ & 0.200 \\
\hline Fever & $1(2 \%)$ & $1(2 \%)$ & 1.000 \\
\hline
\end{tabular}

efficacy of vaginal route, this study was done to explore comparison of vaginal with sublingual route. In this study, we enrolled only postdated pregnancy which is most common indication for induction worldwide. ${ }^{13-16}$ In our study, majority of women who were induced belonged to age group of 20 to 24 years in both groups being we included only primigravidas. Mean age of participants in a similar study reported was $27 \pm 5.2$ in sublingual group and $29 \pm 5.3$ in vaginal group. ${ }^{17}$ Effect of misoprostol on cervical ripening in terms of change in Bishop score showed that vaginal route was more effective compared to sublingual. Augmentation with oxytocin was needed in $34 \%$ of women in vaginal group $(\mathrm{n}=17)$ compared to $66 \%$ of women in sublingual group $(n=25)(p=0.09)$. As in our study no significant difference was seen in need for oxytocin in two routes in other studies. ${ }^{16,17}$

In this study, mean time interval between administration of first dose of misoprostol and delivery was shorter in vaginal group (23.06 \pm 10.93) compared to sublingual group (24.77 \pm 12.81) ( $\mathrm{p}=0.47)$. On the other hand, inductiondelivery interval was much shorter compared to our study and shorter with mean induction- vaginal 
delivery interval was $15.0 \pm 3.7$ in sublingual group and $16.7 \pm 4.1$ in vaginal group. ${ }^{17}$ Comparable finding were shown in other studies. 16,18

Caesarean section rate in other studies were much higher than in our study. 18,19 Instrumental delivery rate was reported as $5.9 \%$ in sublingual and $14.1 \%$ in vaginal group by Nassar et al., $7.1 \%$ in sublingual group and $2.9 \%$ in vaginal group by Bartusevicius et al.16,17 There were three cases of neonatal deaths in the vaginal group $(6 \%)$ and one in the sublingual group (2\%). Similarly, mean Apgar score at five minutes was better in sublingual group $(8.04 \pm 0.92)$ compared to $7.62 \pm$ 1.17 in the vaginal group $(\mathrm{p}=0.05)$. Also, thick meconium stain liquor is lower in sublingual route in our study and previous other studies as well. These findings suggest that sublingual route is better for neonatal perspective than vaginal route but large sample size is required to see any statistical significance. In our study, maternal side effects profile was more in favour of use of vaginal misoprostol as side effects were more in sublingual group. Ten women complained of nausea in sublingual group (20\%) compared to one in vaginal group (2\%) [p = 0.004]. Similarly, five women had vomiting in sublingual group and one case in vaginal group $(2 \%)$. Similar side effect profiles were reported by other studies. ${ }^{16,18}$ It has been speculated that direct effect of vaginal misoprostol on the cervix might contribute to excessive uterine activity, FHR abnormalities and higher rate of meconium stained liquor. ${ }^{20}$ Our study showed that vaginal route was comparatively more effective in cervical ripening compared to sublingual route.

The induction of labor remains a major challenge in modern obstetrics. One systemic review on efficacy and safety of sublingual administration of misoprostol compared to vaginal route showed no statistically significant difference with respect to the rate of vaginal delivery not achieved within 24 hours, uterine hyperstimulation syndrome or caesarean section. ${ }^{19}$ In our study, however, vaginal route appears to be significantly better than sublingual group in terms of improvement in Bishop score and mean induction to delivery interval. However, incidence of meconium stained liquor was seen more in vaginal route. There was no significant difference in need for oxytocin augmentation, caesarean delivery rate and neonatal outcome and maternal side effect and complication in two routes of administration of misoprostol. Our study was limited to two doses of misoprostol for pre-induction cervical ripening among primigravidas.

\section{CONCLUSIONS}

This study showed that vaginal route of misoprostol administration had better effect on cervical ripening as reflected by change in mean Bishop score, mean induction to delivery interval was shorter in the compared to sublingual group. However, women who received misoprostol via vaginal route had significantly higher rate of meconium stained liquor compared to sublingual group. Mean Apgar score after five minutes of delivery was better in the sublingual group than in vaginal. There was no significant difference in neonatal outcome in two groups. Intrapartum maternal side effects were observed more in the sublingual group than vaginal group but was statistically not significant. Hence both sublingual and vaginal routes of misoprostol administration were equally effective for preinduction cervical ripening at term. Both routes appeared safe in this study with fewer maternal and neonatal adverse effects. However, more study in strict setting of randomized controlled clinical trials will be helpful to derive any firm conclusion. 
To cite this article: Acharya I, Thapa S, Chaudhary P. Efficacy and Safety of Sublingual versus Vaginal Misoprostol for Pre-induction Cervical Ripening among Primigravida. MJSBH. 2018;17(1):18-24.

Conflict of Interest: None declared

\section{REFERNCES}

1. Penna LK. Induction of Labour. In; Arulkumuran S, Penna LK, Rao KB editors. The Management of Labour. Chennai:Orient Logman. 2005;281-305.

2. Ventura SJ, Martin JA, Curtin SC, Mathews TJ. Births final data for 1997. National centre for health statistics. National vital Statistics Reports.1999;47:1-96.

3. Cunnigham FG, Gant NF, Levend KJ, Gilstrap III LC, Hauth JC, Wenstrom KD. Willams obstetrics: Induction and augmentation of labour. 21st ED. New York:Mc Graw-Hill. 2003;470-81.

4. Jaana N, Arora N, Biwas SC. Misoprostol in cervical ripening and induction of labour. In;Barik S, Dutta S, Gupta K editors. Misoprostol in obstetrics and Gynecology. New Delhi:Jaypee Brothers; 2005; 70-80. PMCid:PMC543822

5. Carlan SJ, Boldin S, Blust D, O'Berien WF. Safety and efficacy of misoprostol orally and vaginally:A randomized trial. Obstet Gynecol. 2001;98:107-12.

DOI: https://doi.org/10.1097/00006250-200111000-00034

6. Chang $\mathrm{CH}$, Chang FM. Randomized Comparison of misoprostol and dinoprostone for preinduction cervical ripening and labour induction. J Formos Med Assoc. 1997;96:366-9.

PMid:9170825

7. Papanikolaou EG, Plachouras N, Drougia A, Andronikou S, Vlachou C, Stefos T, et al. Comparison of misoprostol and dinoprostone for elective induction of labour in nulliparous women at full term: a randomized prospective study. Reprod Biol Endocrinol. 2004;2(1):70.

DOI: https://doi.org/10.1186/1477-7827-2-70

PMid:15450119

8. Shetty, P. Danielian. Sublingual misoprostol for induction of labour at term. Am J obset Gynaocal. 2002; 186:72-6.

9. Rodney KE. Preinduction Cervical assessment. Clin Obstet Gynecol. 2000;43(3):440-6.

DOI: https://doi.org/10.1097/00003081-200009000-00004

10. Wolf SB, Sanchez-Ramos L, Kaunitz AM. Sublingual misoprostol for labor induction: a randomized clinical trial. Obstet Gynecol. 2005;105(2):365-71.

DOI: https://doi.org/10.1097/01.AOG.0000151992.75614.8d

PMid:15684166

11. Muzonzini G, Hofmeyr GJ. Buccal or sublingual misoprostol for cervical ripening and induction of labour. Cochrane Database system Rev. 2004;18:CD004221.

DOI: https://doi.org/10.1002/14651858.CD004221.pub2 
12. Moraes Filho OB, Albuquerque RM, Pacheco ÁJ, Ribeiro RH, Cecatti JG, Welkovic S. Sublingual versus vaginal misoprostol for labor induction of term pregnancies. Rev Bras Ginecol Obstet. 2005; 27(1):24-31.

DOI: https://doi.org/10.1590/S0100-72032005000100006

13. Weaver SP. Vaginal misoprostol for cervical ripening at term pregnany. American Family Physician 2006;73(3).

14. Lo TK, Lau WL, Wong KS, Tang LC. Sublingual misoprostol compared to artificial rupture of membranes plus oxytocin infusion for labour induction in nulliparous women with a favourable cervix at term. Hong Kong Med Jr. 2006;12(5):345.

PMid:17028353

15. Kolderup L, McLean L, Grullon K, Safford K, Kilpatrick SJ. Misoprostol is more efficacious for labor induction than prostaglandin E 2, but is it associated with more risk? Am J Obstet Gynecol. 1999;180(6): 1543-50.73.

16. Nassar A, Awwad J, Khalil A, Abu-Musa A. A randomized comparison of patient satisfaction with vaginal and sublingual misoprostol for induction of labour at term. BJOG. 2007;114:1215-21.

DOI: https://doi.org/10.1111/j.1471-0528.2007.01492.x PMid:17877674

17. Bartusevicius A, Barcaite E, Krikstolaitis R, Gintautas V, Nadisauskiene R. Sublingual compared with vaginal misoprostol for labour induction at term: a randomised controlled trial. BJOG. 2006;113(12): 1431-7.

DOI: https://doi.org/10.1111/j.1471-0528.2006.01108.x PMid:17083652

18. Zahran KM, Shahin AY, Abdellah MS, Elsayh KI. Sublingual versus vaginal misoprostol for induction of labor at term: a randomized prospective placebo-controlled study. J Obstet Gynaecol Res. 2009;35(6): 1054-60.

DOI: https://doi.org/10.1111/j.1447-0756.2009.01030.x

19. Souza A, Amorim M, Feitosa F. Comparison of sublingual versus vaginal misoprostol for the induction of labour: a systemic review. BJOG. 2008;115:1340-9.

DOI: https://doi.org/10.1111/j.1471-0528.2008.01872.x ～PMid:18823486

20. Danielsson KG, Marions L, Rodrisuez A, Spur BW, Wong PY, Bygdeman M. Comparison between oral and vaginal administration of misoprostol on uterine contractility. Obstet Gynecol. 1999;93:275-80.

DOI: https://doi.org/10.1016/S0029-7844(98)00436-0～PMid:9932569 